\title{
A "Pensar Tu Barrio", proceso participativo para recuperar el espacio público del Casco Norte de Sevilla
}

\author{
"Thinking through Your Neighborhood" a participation process \\ to recover public space. Northern Seville city center
}

\author{
Isabel Jiménez López,* Manuel Calvo Salazar, Kiko Sánchez Díaz, Rafael Ibáñez Reche**
}

Fecha de recepción: 30-04-2016 - Fecha de aceptación: 26-05-2016

Hábitat y Sociedad (ISSN 2173-125X), n. ${ }^{\circ}$ 9, noviembre de 2016, pp. 193-201.

\section{Summary}

Urban renewal processes are essential for a better life in the city. Streets, squares and, ultimately, public spaces are where human interaction,, creativity, diversity and participation occur. Therefore, public spaces are where urban life unfolds, where contacts and connections are made and where the collaborative activities take place.

The current urban model has pushed social interaction from public to private areas. This is mainly due to the presence of new elements which have gradually taken more and more space, such as cars, and also to the lack of equipment to empower public areas. Thus, La Revuelta Neighbourhood Association is promoting a participatory process to design our mobility and accessibility system. The main aim of this process is to jointly and democratically define and transform our neighbourhood regarding the use of our streets and public spaces.

We believe that the role of public spaces should be recovered as a cornerstone in the revitalization of the city and its neigbourhoods, to encourage social interaction and to increase urban sociability and social cohesion.

\section{Key words}

Citizenship, Participation, Public Space, Mobility, Livability, accessibility

\section{Resumen}

Los procesos de renovación urbana son esenciales para el desarrollo de la vida en la ciudad. La calle, la plaza, el espacio público en definitiva, representan lugares de encuentro, diversidad y participación, entendiendo el espacio público como el lugar donde se desarrolla la vida urbana, el espacio de relación en el que se producen contactos y conexiones entre los habitantes y posibilita la realización de actividades colectivas.

La ciudad actual ha relegado los espacios de relación de ámbitos públicos a privados, fundamentalmente provocado por la presencia de nuevos elementos que paulatinamente han adquirido más presencia, como es el coche, o la inexistencia de equipamientos que cualifiquen el espacio público. Es por ello por lo que desde la asociación vecinal La Revuelta se impulsa un proceso para diseñar de manera participada el sistema de movilidad de nuestro barrio, cuyo objetivo principal es el de definir de manera colectiva y plural cómo es el barrio que queremos respecto al uso de las calles y del espacio público.

Entendemos que es necesario recuperar el papel que los espacios públicos juegan en nuestra ciudad como pieza fundamental en la revitalización como lugares cargados de encuentros y sentimientos, que dan cabida a numerosos encuentros fortuitos, entendiéndolos como el lugar de encuentro y sociabilidad urbana.

\section{Palabras clave}

Participación Ciudadana, Espacio Público, Movilidad, Habitabilidad Urbana

\footnotetext{
* Prof. ETSA Sevilla. Correo: isabeljimanez@us.es.

** Asociación Vecinal del Casco Norte de Sevilla, “La Revuelta”. Correo: correo@larevuelta.org. Colaboraciones: Soraya Salas (logística), Concha Ortiz (traducción), miembro de AICE.
} 


\section{La necesidad de recuperar el Espacio Público}

Una escena callejera: un día cualquiera en una calle cualquiera. Los peatones caminan por las aceras, los niños juegan delante de los portales, la gente está sentada en bancos y escalones, el cartero hace su recorrido con el correo, dos transeúntes se saludan en la acera, dos mecánicos arreglan un coche, algunos grupos conversan (Gehl, 2004, p. 17).

Entendemos el espacio público, como el lugar donde se desarrolla la vida urbana, un espacio de relación en el que se producen contactos y conexiones entre los habitantes y posibilita la realización de actividades colectivas. Dice Jacobs que: "Las calles y sus aceras son los principales lugares públicos de una ciudad, sus órganos más vitales" [...]. "Son un medio de comunicación y contacto, una autentica institución social de la ciudad" (Jacobs, 1961, p. 33).

En este sentido, el arquitecto Allan Jacobs (1996, p. 17) identifica que "Las calles son lugares de encuentro e intercambio, desde el punto de vista social y comercial, son el medio donde las personas se encuentran con otras y esto es, al fin y al cabo, la principal razón de ser de las ciudades". Identifica a las calles como lugares cargados de encuentros y sentimientos, que dan cabida a numerosos encuentros fortuitos, entendiéndolas como el lugar de encuentro y sociabilidad urbana. Las calles son, por tanto, un espacio que por su propia naturaleza facilita la vida colectiva en la ciudad, que posibilita el encuentro convirtiéndolas en la estructura más importante de la ciudad donde se puedan desarrollar innumerables escenas de gran diversidad. De este modo la calle cobra un importante valor en la actualidad, si en un principio se entendía como un mero espacio de circulación, en estos momentos la entendemos como el espacio de relación y desarrollo de la vida cotidiana y urbana de la ciudad.

La necesidad de estudio del espacio público se hace cada vez más patente como espacio de relación sociocultural, dejando de un lado o minimizando su concepción administrativa y legal vinculada a un área de la ciudad exenta de edificación para uso público, y asignándole cualidades como un lugar de relación y de identificación, de contacto entre las personas, de animación urbana, y a veces de expresión comunitaria" (Borja y Muxi, 2000, p. 27).

Borja plantea la necesidad de un nuevo enfoque de análisis de las dinámicas urbanas a través del "estudio del espacio público y la relación existente entre su configuración y el ejercicio de la ciudadanía, entendida como el estatuto que permite ejercer un conjunto de derechos y deberes cívicos, políticos y sociales" (Borja, 1998).

Para ello, es necesario entender el espacio público como un espacio, que por su propia naturaleza facilita la vida colectiva en la ciudad, que posibilita el encuentro convirtiéndolo en la estructura más importante de la ciudad donde se puedan desarrollar innumerables escenas de gran diversidad. De este modo la calle cobra un importante valor en la actualidad, si en un principio se entendía como un mero espacio de circulación, en estos momentos la entendemos como el espacio de relación y desarrollo de la vida cotidiana y urbana de la ciudad.

En esta misma línea Borja y Muxi definen los espacios libres como espacios no residuales entre las edificaciones, sino que un espacio público es al mismo tiempo el principal espacio de la ciudadanía y un espacio que tiende a la mezcla social. Esta integración en el espacio urbano se consigue a través de un espacio público, que "favorece la 
multifuncionalidad y se vuelve un elemento de potencialidad evolutiva. El espacio cotidiano es el de los juegos, de las relaciones casuales o habituales con los otros, del recorrido diario entre las diversas actividades y del encuentro. Este espacio coincide con el espacio público de la ciudad. Por eso favorecer el espacio público dándole cualidades estéticas, espaciales y formales facilita las relaciones y el sentimiento de pertenencia al lugar. Además estas cualidades permiten el uso del espacio por parte de todos sin excluir a nadie" (Borja y Muxi, 2000, p. 93).

La presencia del automóvil y su uso abusivo ha desplazado a las personas de las calles y el resto de usos que esta tienen que tener en una ciudad viva. Adicionalmente, la invasión por otros elementos, como la presencia abusiva de veladores, han ido generando un paulatino abandono, banalización y monofuncionalidad del espacio público. Esta degradación ha provocado a lo largo del tiempo la "desaparición de la vida en la calle".

Desde la Asociación Vecinal "La Revuelta" creemos que ya es hora de cambiar esto. Que las personas que vivimos el barrio pensemos en mejorar la vida en el espacio público del barrio, con nuestras cabezas, nuestras emociones y nuestra forma de sentirlo. La zona norte del Casco Antiguo es nuestro barrio. Lo queremos vivo, alegre y habitable.
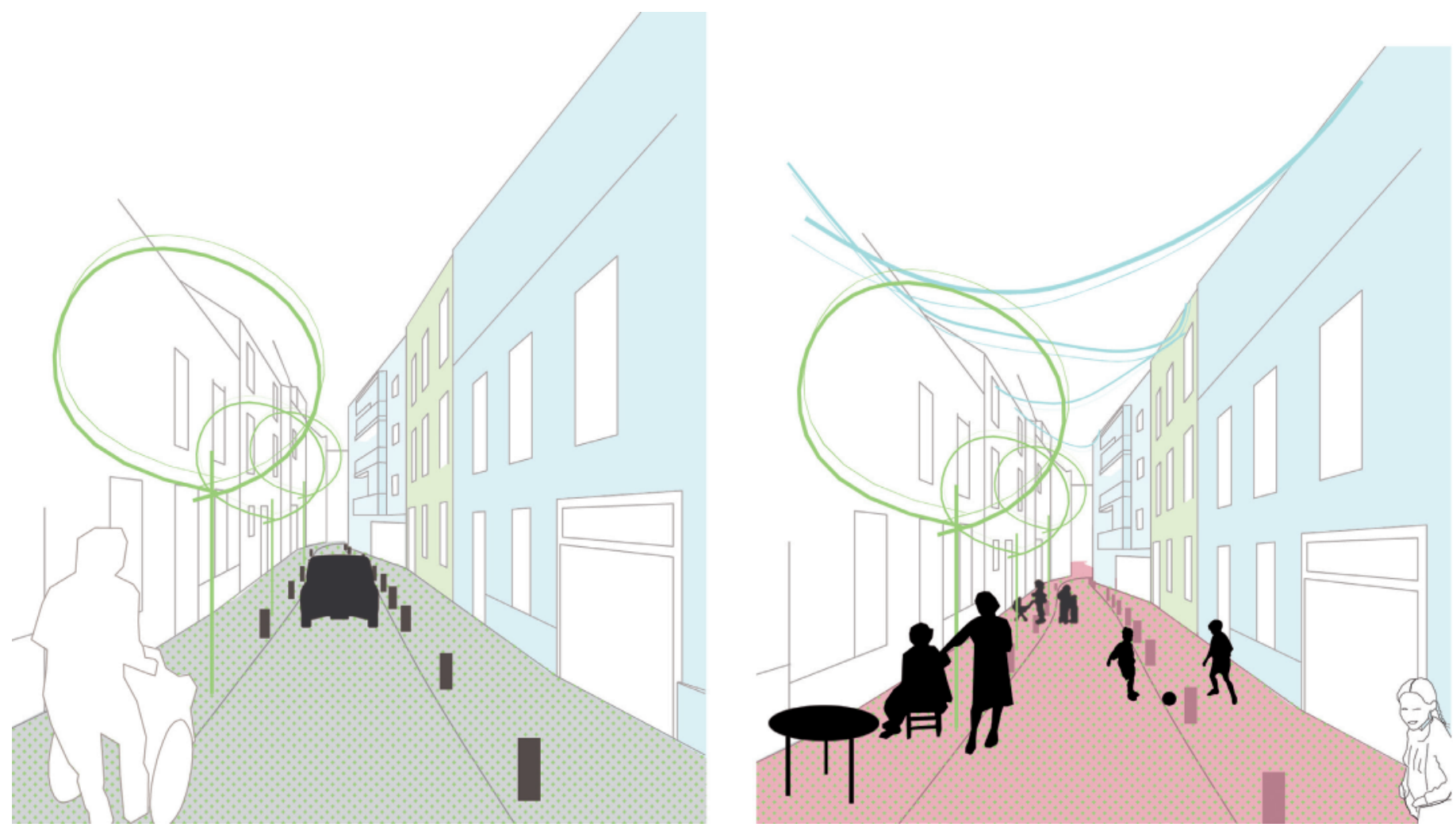

Por esta razón nos parece fundamental, en un intento de recuperar el espacio público, diseñar una estrategia de participación ciudadana que cuente con todas las personas, sus experiencias y necesidades, para proponer un barrio que responda realmente a la diversidad de todas y todos.
Figura 1. Una calle de Sevilla. Fuente: Isabel Jiménez. 


\section{La participación como construcción colectiva}

Actualmente los procesos de participación pública en el planeamiento general son prácticamente inexistentes, o se reducen a un periodo de alegaciones o sugerencias que aunque denominen "participación" no deja de ser un proceso de consulta al procedimiento ya iniciado.

Reconocer el proceso de participación como un hecho colectivo previo a los inicios del desarrollo urbano, supone, primero, tener conocimiento de quiénes son los sujetos que participan en la ciudad, quién compone la ciudad habitada. Reconocer que la ciudad la forman sujetos de diferentes sexos, edades, etnias, y que es imprescindible detectar y conocer la diversidad para no generar la desigualdad. "El desarrollo de la vida cotidiana de los intervinientes en el funcionamiento de la ciudad usan y tienen una experiencia del entorno urbano diferente, de acuerdo con los roles y responsabilidades asignadas a cada individuo" (Muxi, Casanovas, Ciocoletto, Fonseca, Gutiérrez, 2011, pp. 105-129).

Desde La Revuelta apostamos y creemos en los procesos participativos públicos de abajo arriba, en los que el uso de la palabra "participación" no se convierta en un mero eslogan publicitario e invertir el proceso para trabajar desde el barrio. Rechazamos la participación limitada a la opinión sobre lo que hace de forma opaca y cerrada la ofi-

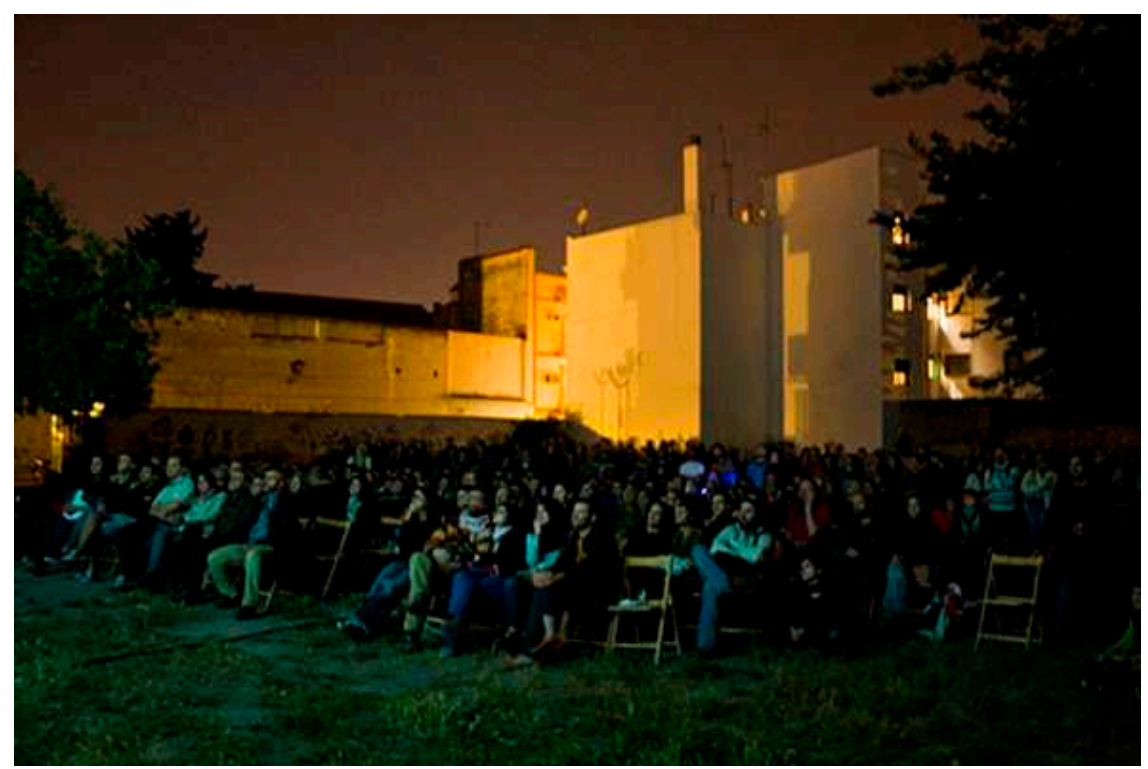
cialidad. "No queremos opinar sobre los guisos hechos a espalda de la gente, queremos compartir la cocina”.

No es la primera vez que la experiencia colectiva del barrio ha conseguido determinar y modificar el planeamiento oficial a través de acciones salidas de la gente. El barrio ha conseguido en muchas ocasiones ejercer el derecho al plan: Casa Pumarejo, Huerto del Rey Moro, CEIP Huerta de Santa Marina, por ejemplo. Y son estas acciones las que generan en los vecinos y vecinas la capacidad de identificarse y encontrarse en su espacio público con un mayor sentimiento de apropiación del mismo.

Figura 2. Acciones ciudadanas en el Huerto del Rey Moro.

\section{Antecedentes y experiencias de la asociación}

Tras una época de la ciudad de Sevilla por la que se apostó desde el ámbito municipal por el avance en las políticas de recuperación del espacio público y la movilidad sostenible: peatonalización de la calle San Fernando, Puerta Jerez, Asunción, San Jacinto, y en su práctica totalidad Alameda de Hércules, puesta en marcha del tranvía, red de vías ciclistas, limitación al vehículo no residente en el casco antiguo, etc. La llegada del gobierno municipal del PP supuso una importante regresión en el modelo impulsado con anterioridad.

La Asociación Vecinal del Casco Norte "La Revuelta" fue especialmente combativa con la nueva política que pretendía invertir hacia el pasado el modelo de espacio público y movilidad, acuñando, a través de su blog, La Mirada Revoltosa, un término que partiendo del apelli- 
do del alcalde, distintos ámbitos sociales, mediáticos y académicos hicieron suyo: La Zoidociudad.

Así, la Zoidociudad definía un modelo de ciudad, en la que desaparecía la limitación de acceso del vehículo privado no residente por la estrecha trama del casco histórico, la Zoidomovilidad, planteaba levantar la zona peatonal de la plaza más grande de Europa, La Alameda de Hércules, para construir un enorme aparcamiento, el Zoidoparking, o privatizar el espacio público eliminando bancos de las plazas y colonizándolos de veladores.

Tras las elecciones y el cambio político en el Ayuntamiento y a pesar de las promesas de reconducir esas políticas, la inacción se apodera del gobierno local, las premisas de la Zoidociudad siguen vigentes, ante esta situación desde La Revuelta se decide pasar a la acción: "Ya no esperamos a los burócratas, animamos al barrio a pensar, actuar y proponer un Plan Barrio"

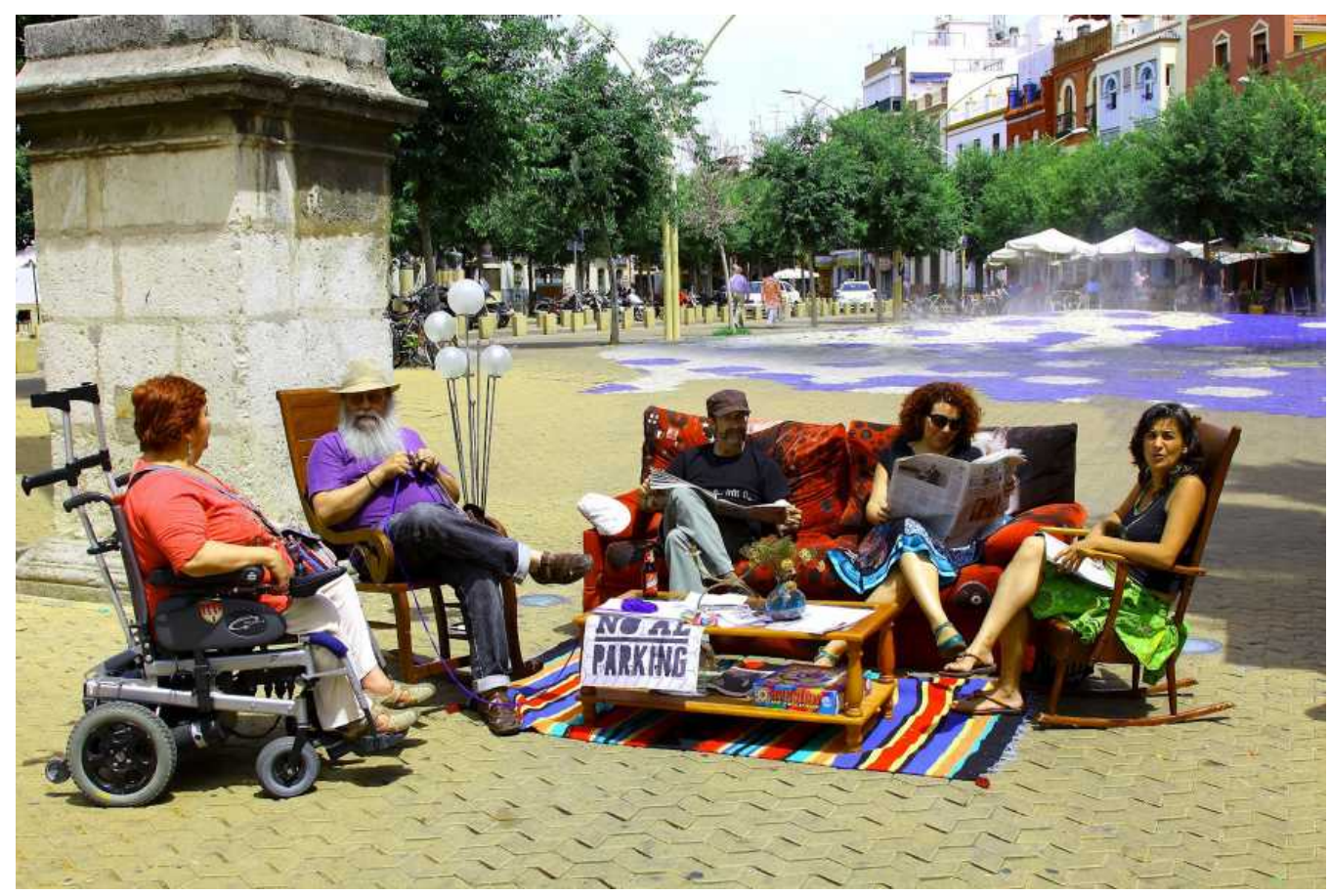

\section{La metodología y el proceso}

Figura 3: Acciones ciudadanas antiparquin.

El Plan Barrio es una metodología sencilla para hacer un diagnóstico efectivo y rápido y proponer un Plan. Este proceso se puede realizar en un corto espacio de tiempo y el resultado puede reflejarse en solo dos planos.

El formato claro y sencillo sintetizando las propuestas del Plan lo convierte en un instrumento que facilita la participación y el diálogo entre los diferentes colectivos y gestores de la ciudad y la población destinataria que se ven empoderados participando en la planificación de la mejora de su hábitat.

El derecho que todos los ciudadanos tenemos a la ciudad se transforma en el "Derecho al Plan", que es lo mismo que decir el derecho a la ciudad que queremos. Porque un Plan debe reflejar las aspiraciones, las necesidades, los conflictos, las soluciones, que un colectivo expresa para su entorno físico y social.

En esta primera experiencia de Plan Barrio participativo del Casco Norte del Centro Histórico de Sevilla se abordó el tema de la movilidad y espacio público, en el que se identificaron a lo largo de tres horas los problemas y posibles soluciones para nuestro barrio, y donde están los conflictos que hay que resolver, a partir del trabajo en grupo, las discusiones y puesta en común, de manera que el vecindario plasmó sus ideas sobre unos planos y tuvo la oportunidad de ponerlas en común y debatirlas.

La jornada titulada "Pensar tu barrio", en la que vecinos y vecinas 


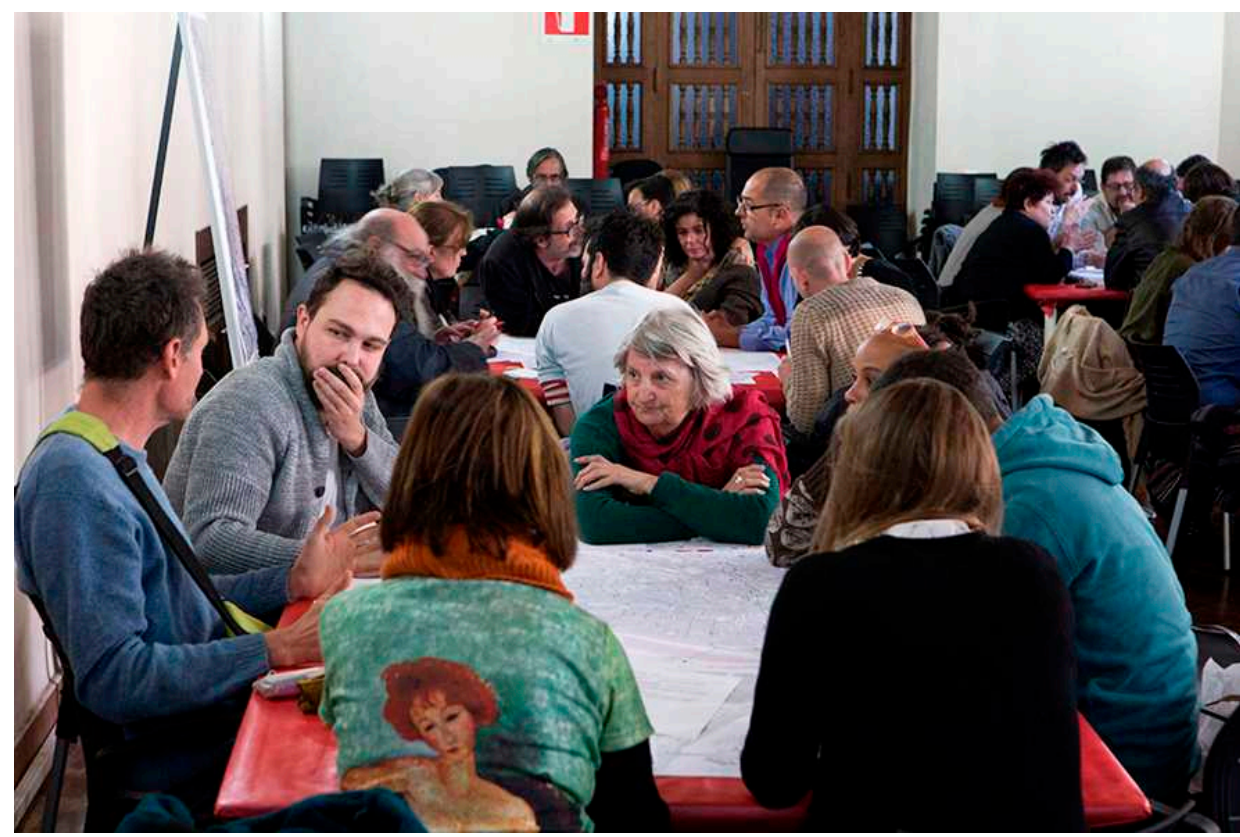

Figura 4. Jornadas de trabajo. Marqueses de la Algaba. Fuente: Concha Laverán.

Figura 5. Jornadas de trabajo. Marqueses de la Algaba. Fuente: Concha Laverán.

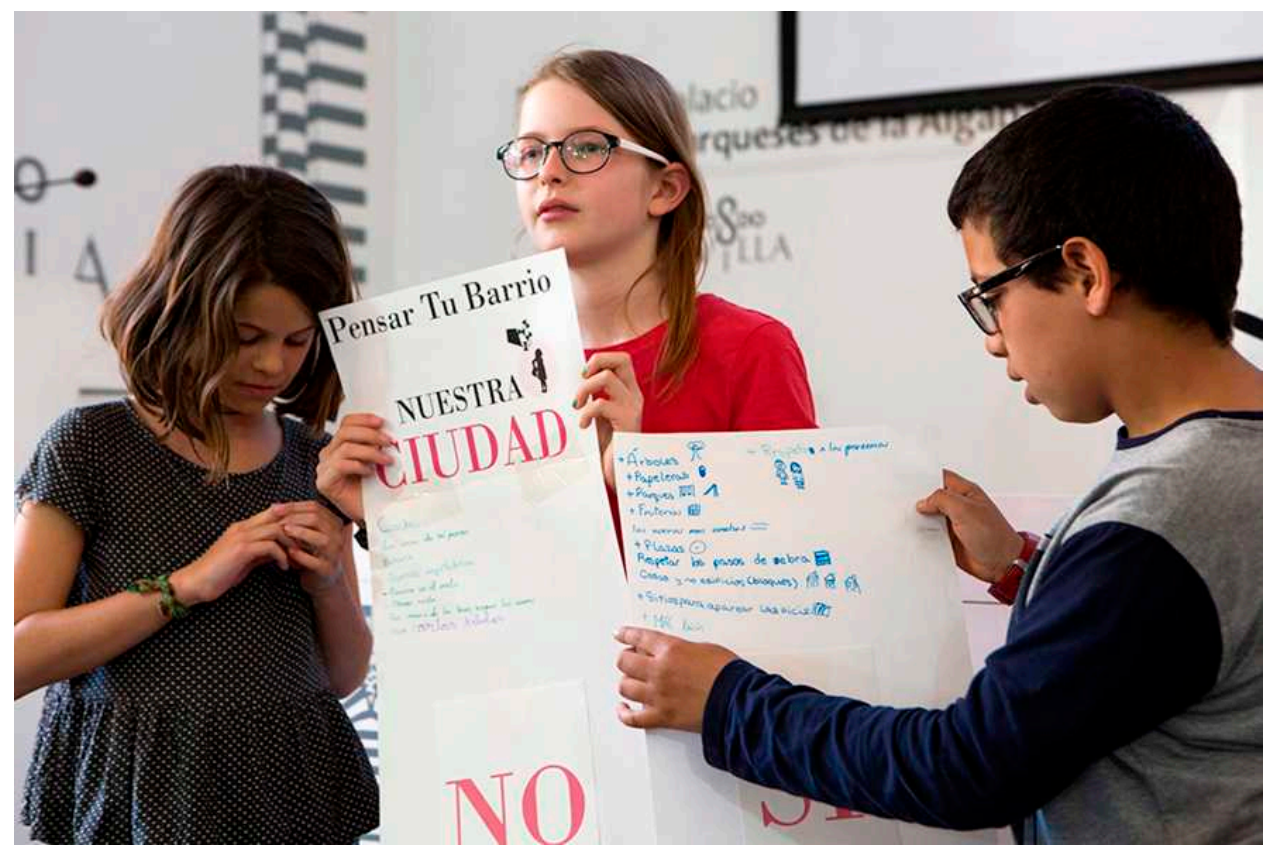

organizados en 7 mesas de trabajo - una de ellas formada por menores - han diseñado cómo quieren que sea el Casco Norte de Sevilla en cuanto a transporte público, itinerarios peatonales, vías ciclistas, arbolado, veladores, bancos, plazas o aparcamientos. Tres horas intensas de trabajo, un grupo de gente volcada en pensar en sus espacios comunes y un ejemplo de cómo organizar un proceso realmente participativo.

La realización de estas jornadas, con su documento propositivo de síntesis, pretende ser el inicio de un proceso impulsado por la propia ciudadanía que ayude a que se ejecuten medidas y actuaciones concretas "sobre el terreno". Así, y como ejemplo, están la de mejorar la relación con el río, que pasa por repensar la función y la morfología de la calle Torneo; o la de potenciar y mejorar la trama de las plazas y parques del casco histórico, mediante su conexión con una red de calles de preferencia peatonal-ciclista que ponga en valor este patrimonio y lo haga más habitable. Y entre las más concretas y sencillas de realizar, apuntar la creación de pasos peatonales; o la mejora del mobiliario de determinados espacios públicos; o la optimización de la gestión y uso de algunos de estos espacios para compatibilizar mejor su uso comercial (veladores) con el resto de usos ciudadanos, de tránsito, de estancia, de juego...

La regeneración del Casco Norte apuesta por una recuperación del espacio público para la ciudadanía, una regeneración amable y que genere mayor cohesión social, mejorando cualitativamente la calidad de vida, desde lo ambiental, con la disminución del tráfico rodado, hasta lo social provocando que vuelva la vida a la calle y mejorando los niveles de seguridad. Un elemento clave para la disminución del tráfico rodado, han sido las propuestas encaminadas a la mejora de la peatonalidad y de las condiciones de la movilidad ciclista.

Apostar por reconquistar el espacio público y rehabitar de nuevo la calle conlleva un cambio en la metodología y procesos de intervención en la ciudad consolidada. La propuestas no se abordan desde grandes y costosas intervenciones sino más bien en la reparación del uso y no del soporte, a través de acupunturas urbanas que mejo- 


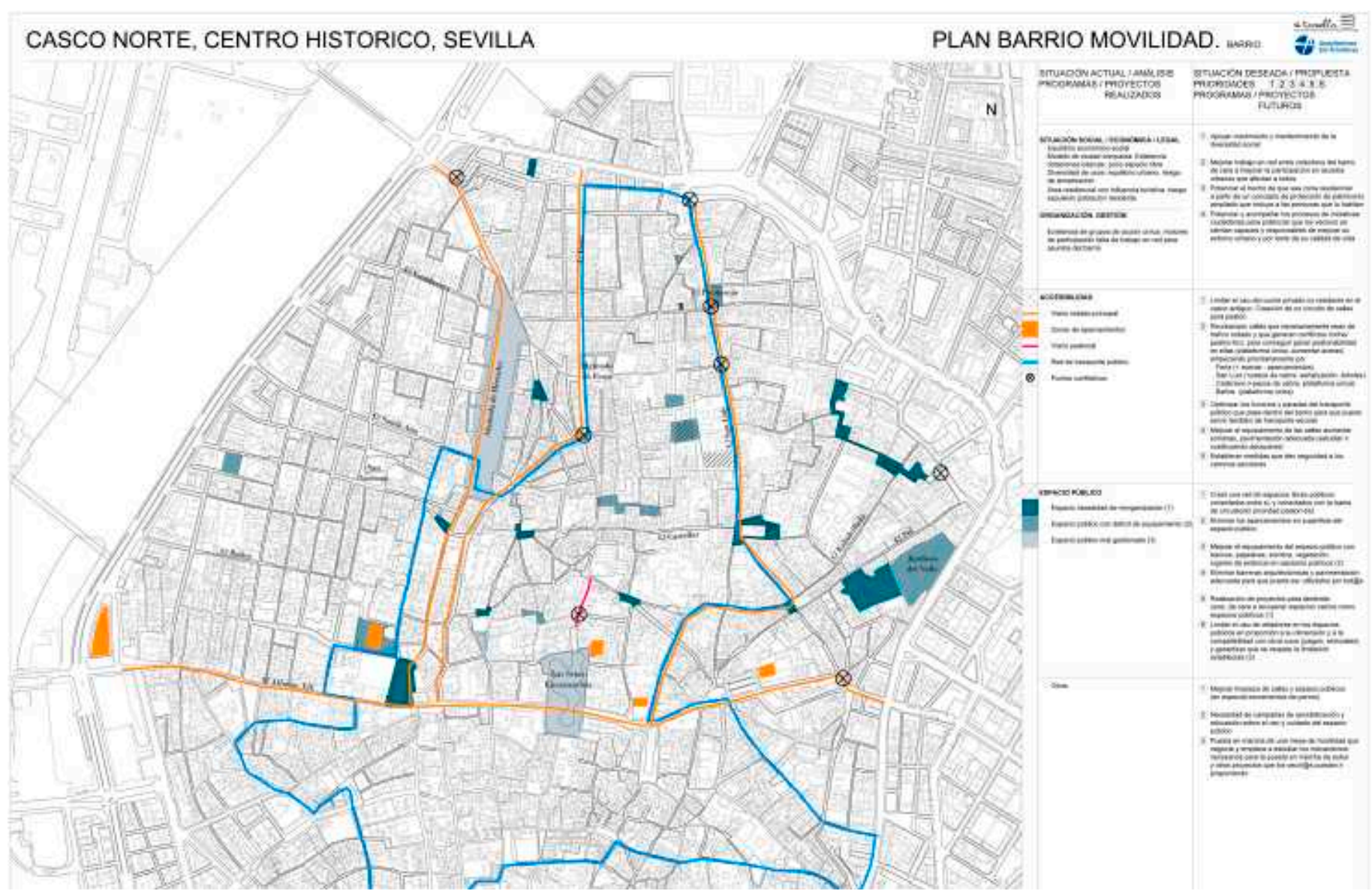

ren la calidad de vida urbana. El objetivo es cambiar la funcionalidad de las calles y no necesariamente su morfología. Esta metodología de intervención permite incidir en la mejora de las condiciones del espacio público sin tener que esperar a intervenciones caras y que conlleven un trámite administrativo largo. Es decir, la propuesta que se está construyendo está pensada para que sea efectiva "desde ya", para que ese espacio público recuperado pueda cumplir su función en un plazo de tiempo lo más corto posible. La idea es invertir más recursos y tiempo en pensar y diseñar mediante procesos participativos y menos en obras y demás procesos costosos.

Esto no ha hecho más que empezar. El proceso se ha iniciado con la puesta en común de propuestas, proyectadas en planos del barrio, continúa con la difusión y debate de las mismas, a fin de tejer consensos, enriquecer las propuestas originarias y favorecer que surjan otras nuevas. Para ello, La Revuelta ha organizado un grupo motor que impulsa los distintos grupos de difusión y acompañamiento de las propuestas concretas, ha desplegado herramientas informáticas de participación, orga-
Figura 6. Mapa de conclusiones. Fuente: Elaboración propia.

Figura 7. Dibujo Plaza Calderón de la Barca. Fuente: Isabel Jiménez.
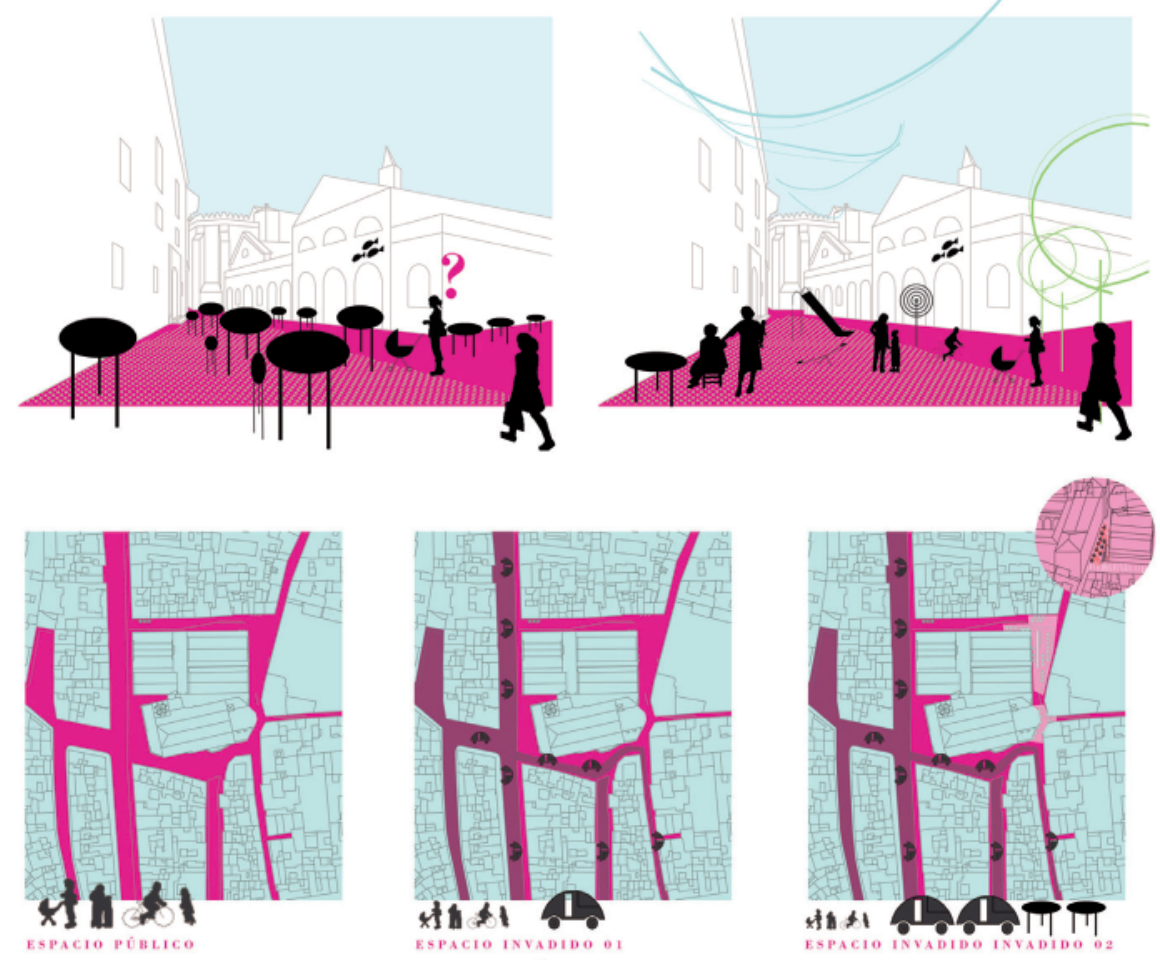

RECUPERAR EL ESPACIO PÚBLICO PARA LOS CIUDADANOS 
nizado encuentros, exposiciones presenciales, etc. De todo este proceso va quedando un relato en la página web de la asociación www.larevuelta.org .

Los vecinos y vecinas del Casco Norte se han pronunciado y seguirán haciéndolo, hasta ahora lo tienen bastante claro:

- Queremos un casco antiguo en el que las personas que se mueven en modo peatón o ciclista tengan más fácil el tránsito sin calles prohibidas por señales o porque el espacio es monopolizado por los coches.

- Un barrio sin aceras imposibles, barreras arquitectónicas o adoquines que maltratan a quien se mueve sin motor.

- En los espacios públicos estamos, hablamos, compartimos, jugamos, construimos tribu.

- Queremos más vegetación en nuestras calles y plazas.

- No queremos veladores que lo invadan todo. Queremos que guarden una proporción sensata, acorde a la capacidad del espacio público, no de la máxima producción que alcancen sus barras y cocinas.

- Nuestras plazas deben ser más aún espacios colectivos. No las queremos privatizadas. Deben tener mobiliario para un uso adecuado, bancos, papeleras, iluminación correcta y sostenible. 


\section{Bibliografía}

Borja, J. (1998). Ciudadanía y espacio público, Urbanitats" 7: Ciutat real, ciutat ideal. Significat i funció a l'espai urbà modern, CCCB, Barcelona. Recuperado el 15 de octubre de 2016, de: http://urban.cccb.org/ urbanLibrary/htmlDbDocs/A011-B.html.

Borja, J. y Muxi, Z. (2000). El espacio público, ciudad y ciudadanía, Barcelona. Recuperado el 15 de octubre de 2016, de: http:/ / www.esdi-online.com/repositori/public/dossiers/DIDAC_wdw7ydy1.pdf.

Gehl, J. (2004) (Trad. esp. 2006). La humanización del espacio urbano: la vida social entre los edificios. Barcelona: Editorial Reverté.

Jacobs, A. (1996) Grandes calles. Madrid: Publicaciones de la Universidad de Cantabria.

Jacobs, J. (1973). Muerte y vida de las grandes ciudades. Madrid: Ediciones Península

Muxi, Z., Casanovas, R., Ciocoletto, A., Fonseca, M. y Gutiérrez, B. (2011). ¿Qué aporta la perspectiva de género al urbanismo? Feminismo/s, 17, 105-129.

JIMÉNEZ LÓPEZ, Isabel; CALVO SALAZAR, Manuel; SÁNCHEZ DÍAZ, Kiko e IBÁNEZ RECHE, Rafael. A "Pensar Tu Barrio", proceso participativo para recuperar el espacio público del Casco Norte de Sevilla. Hábitat y Sociedad, 2016, n. ${ }^{\circ}$ 9, pp. 193-201. <www.habitatysociedad.us.es>

http://dx.doi.org/10.12795/HabitatySociedad.2016.i9.10

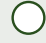

